\title{
AOR
}

Selected Papers of \#AolR2020:

The $21^{\text {st }}$ Annual Conference of the Association of Internet Researchers

Virtual Event / 27-31 October 2020

\section{DIGITAL DETOX CAMP: VALUES AND MOTIVATIONS FOR ENGAGING IN DIGITAL DISCONNECT}

\author{
Faltin Karlsen \\ Kristiania University College
}

\section{Introduction}

Media users increasingly express ambivalence about their own media consumption, often related to ubiquitous media technology such as the smartphone and social media (Syversen 2020). This has fostered public debates about the need to cut down on media use, and more research on the topic has been requested (Woodstock 2014, YtreArne and Das 2019). In order to understand the growing trend of disconnection as a cultural and social phenomenon and more than a sum of individual choices and selfhelp practices, we conducted an analysis of the digital detox inspired camp for grownups Underleir, which has been arranged in Norway annually since 2014. The aim was to study what kind of norms and values that had motivated participants to take part in this temporary media hiatus.

\section{Methods and material}

The main empirical material stems from a field study of the camp Underleir in 2019 where two researchers conducted participatory observation on a four-day field trip. We had informal talks with 30 of the participants - of a total of around 50 - and conducted in-depth interviews with three participants and one of the organizers. The initiative to the camp came from one of the participants of the Norwegian social network site Underskog, and we included material from this site about the camp from the inception in 2014 to the sixth installment in 2019. This combination of material gave us the opportunity to contextualize this particular camp event, providing us with an outline of

Suggested Citation (APA): Karlsen, F. (2020, October 28-31). Digital detox camp: Values and motivations for engaging in digital disconnect. The $21^{\text {th }}$ Annual Conference of the Association of Internet Researchers. Virtual Event 27 / 31 October 2020. Retrieved from http://spir.aoir.org. 
how norms, rules, and activities evolved over time. Field notes, the interviews and online data was coded and analysed in Nvivo.

\section{Theoretical framework}

The main theoretical approach for this analysis is media domestication theory with special attention to the concept reverse domestication. In contrast to the domestication process where new media technology is "tamed", reverse domestication implies cognitive processes and practical strategies involved when distancing from media technology (Karlsen and Syvertsen 2016).

\section{Guidelines and media norms}

Underleir is inspired by the U.S. based camp, Camp Grounded, and has adopted many of their rules, aiming to enhance a positive and relaxing atmosphere (Sutton 2017). Rules directed toward media technology have informal formulations such as "Don't be online" because "it is so incredibly difficult to play with someone while simultaneously checking Facebook." The official camp rules have been relatively stable over time but were still part of an ongoing negotiation among participants. We observed also instances where rules were transgressed, such as people using their smartphone to google for information. In some cases, this created a tension between experienced participants and newcomers defending their breach as exceptions, arguing that retrieving "static" information was not in breach with the spirit of the rules. The general impression was that participants had different interpretations of the underlaying intentions of the rules, what sort of activities they were meant to inspire, and what values they promoted.

\section{Organised activities - time and space}

According to domestication theory, how much time and space (referred to as objectification and incorporation) a new medium is allowed to occupy in the household is part of the normative process of domesticating new media technology (Silverstone and Hirsch 1992). Accordingly, temporal and spatial aspects are important for the reverse process (Karlsen and Syvertsen 2016). At Underleir, routines and activities were predominantly regulated by elements other than media. While the participants could choose freely what to spend their time on, the majority engaged in some forms of organised activities during the day, such as yoga, crocket play, and fishing, or prepayed courses with professional instructors on activities such as wood cutting and jammaking. As many of the participants didn't wear watches the meals served as temporal guidelines signaling when activities had to stop. The participants were also split up from their activities, preventing formation of groups. Since no one, at least officially, could communicate digitally, the participants were prevented from orienting themselves about coming activities, and the meals become an important hub for exchanging information about changes in program, to raise suggestions for coming activities and other vital information.

\section{Normative boundaries}

The restrictions on media use at Underleir, including legacy media like television, radio and newspapers, played an important role in the experience of being separated from the outside world. It was a noticeable absence of information about current affairs and 
no discussions about Trump's presidency, Brexit or other hot topics, at least as we witnessed. However, as the rule negotiation and smartphone use show, the barrier to the outside world had certain breaches, and they were not arbitrary. Information were in certain circumstances regarded as acceptable to approach, while communicating with the outside world would imply too much of a transgression. The wealth of activities being offered also served as an inexhaustible well of stimulating input, much like how smartphones and laptop may otherwise do. Several of the participants expressed reminiscent of their childhood holidays or camp experiences where the social life was intense and "the summers seemed endless" as one informant expressed it.

\section{Findings}

Underleir illustrates how practical, social, and normative aspects may be interwoven when media use is reversed or altered. Normatively speaking, the digital detox experience was tied to broader sets of values, including an aim for a more creative, authentic life and a quest for mental wellbeing and the ability to focus. Many participants stated that the opportunity to engage in creative activities, and to be social in a friendly setting, was just as important as the absence of media. When media abstention was explicitly mentioned many participants explained that engaging in physical activities gave them a sense of focus and flow they weren't able to experience in their daily life when digital media was available. This was coupled to the value of being able to engage more deeply in a subject, compared to the "shallowness" of media use. It was further described as an opportunity to have more "authentic" experiences than the media could offer. In many ways, the norms described by the participant mirror general media debates and traditional concerns for media. In addition to this, however, the participant clearly also expressed the importance of being in a creative space where you could play and have fun, reminiscent of earlier times with less demands and pressure. In this sense, the camp simply provided an opportunity to escape stressful jobs and the demands of adult life, just as much as a life without digital media.

\section{References}

Karlsen, F., \& Syvertsen, T. (2020). You can't smell roses online: Intruding media and reverse domestication. Nordicom review, 37(s1), 25-39

Silverstone, R. \& Hirsch, E. (eds.) (1992). Consuming Technologies: Media and Information in Domestic Spaces. London and New York: Routledge.

Sutton, T. (2017). Disconnect to reconnect: The food/technology metaphor in digital detoxing. First Monday, 22(6).

Syvertsen, T. (2020). Digital Detox: The Politics of Disconnecting. Emerald Group Publishing.

Woodstock, L. (2014). "Media resistance: Opportunities for practice theory and new media research," International Journal of Communication, volume 8, number 19, pp. $1,983-2,001$

Ytre-Arne, B., \& Das, R. (2019). An agenda in the interest of audiences: Facing the challenges of intrusive media technologies. Television \& New Media, 20(2), 184-198. 